\title{
Effect of sidr honey on healing of contaminated wounds in alloxan-induced diabetes mellitus in dogs
}

\author{
Musa A. Alshehabat*1, Zuhair A. Bani Ismail ${ }^{1}$, Wael M. Hananeh' ${ }^{2}$, and Mofleh S. Awawdeh² \\ ${ }^{1}$ Department of Veterinary Clinical Sciences; ${ }^{2}$ Department of Pathology and Public Health, Faculty of Veterinary \\ Medicine, Jordan University of Science and Technology, Irbid 22110, Jordan
}

\section{Article history}

Received: 1 Oct, 2016

Revised: 22 Oct, 2016

Accepted: 23 Oct, 2016

\begin{abstract}
The objective of the study was to compare Sidr honey and iodine on healing of contaminated wounds in induced diabetes in dogs. Diabetes mellitus was induced in dogs $(\mathrm{n}=4)$ using intravenous injection of $120 \mathrm{mg} / \mathrm{kg}$ alloxan monohydrate. Status of the diabetes was verified using oral glucose tolerance test. Four $(1.5 \mathrm{~cm} \times 1.5 \mathrm{~cm})$ wounds were created on each of the research subject's back. Wounds were covered with $2 \mathrm{gm}$ of dog feces under a bandage for 24 hours prior to starting the treatments. In each of the diabetic dogs or control $\operatorname{dogs}(n=4), 2$ wounds $(n=8)$ were treated with 1-2 $\mathrm{ml}$ of $10 \%$ povidine iodine and 2 wounds $(\mathrm{n}=8)$ were treated with $1-2 \mathrm{ml}$ of pure Sidr honey. Treatments started twice daily for the first week and then once daily for the rest of the study. Wounds were left to heal by second intention healing. Healthy control dogs were treated in a similar fashion. Wounds in the alloxan-induced diabetic dogs healed at a slower rate. In both groups, honey or iodine treated wounds appeared to heal at a comparable rate. Sidr honey can be considered as a safe natural remedy to manage contaminated wounds.

Keywords: Dogs; alloxan; contaminated; wounds; Sidr
\end{abstract}

\footnotetext{
To cite this article: Alshehabat MA, ZAB Ismail, WM Hananeh and MS Awawdeh, 2016. Effect of sidr honey on healing of contaminated wounds in alloxan-induced diabetes mellitus in dogs. Res. Opin. Anim. Vet. Sci., 6(8): 242-247.
}

\section{Introduction}

Diabetes mellitus is considered an incurable and chronic metabolic disorder that is of great health significance in human and veterinary medicine. It is usually associated with serious complications including poor or slow wound healing (Nelson and Reusch, 2014). In veterinary medicine, managing poorly healing wounds, infected or complicated wounds can be devastating and costly particularly in diabetic or immunocompromised animals (Ullah et al., 2015). In human medicine, the incidence of "foot ulcer" secondary to diabetes mellitus is high and is considered one of the most common causes of lower limb amputations and poor quality of life (Margolis et al., 2005).

The efficacy of many conventional wound-dressing medicinal products has been investigated with controversial outcome. Several natural products including honey have been promisingly reported to promote and optimize the process of wound healing (Kamaratos et al., 2014). However, most of the research

*Corresponding author: Dr. Musa A. Alshehabat, Department of Veterinary Clinical Sciences, Faculty of Veterinary Medicine, Jordan University of Science and Technology, Irbid 22110, Jordan Email: maalshehabat@just.edu.jo; Fax: + 962-2-7095123; Tel: +962-2-7201000 
conducted was solely to evaluate the effect of the medicinally proven types of honey in selected regions of the globe. Recently, there has been growing body of research suggesting a promising effect of a mono-floral honey, "Sidr honey", that is indigenous to the Arabian Peninsula (Alzubier and Okechukwu, 2011). Sidr honey has been suggested to promote wound healing (Hananeh et al., 2015). Therefore, the broad objective of the research reported here was to investigate the effect of Sidr honey on the healing of full thickness contaminated wounds following alloxan-induced diabetes mellitus in dogs. Our hypothesis is that topical application of Sidr honey will promote faster healing of contaminated wounds when compared with iodine.

\section{Materials and Methods}

The study protocol was reviewed and approved by the Institutional Animal Care and Use Committee (IACUC). All conducted procedures performed in the study presented here were in accordance with the institutional ethical standards.

Eight healthy mixed-breed dogs were obtained from a local breeder. The mean body weight was $20 \pm 2$ kg. Comprehensive physical examination was performed and blood analysis was conducted prior to the start of the study. Only healthy dogs were included in the study. Animals were randomly allocated into 2 groups: alloxan-induced $\operatorname{dogs}(\mathrm{n}=4)$ and control group $(n=4)$. Diabetes mellitus was induced by a single intravenous injection of $120 \mathrm{mg} / \mathrm{kg}$ alloxan monohydrate (LKT Laboratories, Inc., MN, USA) of fasting dogs as previously described (Bani Ismail et al., 2015). Dogs in the control group were injected a comparable amount of sterile saline.

Dogs in the alloxan-induced group were subjected to oral glucose tolerance test (OGTT) before induction of diabetes to verify lack of preexisting naturally occurring diabetes mellitus. The OGTT was repeated a week post-induction to verify status of diabetes mellitus. Dogs with blood glucose of $\geq 200 \mathrm{mg} / \mathrm{dl}$ at 3 hours post-glucose administration were considered consistent with diabetes mellitus. Blood glucose level was monitored every 2 hours using Acura blood glucose meter (US Diagnostics, Inc., New York, USA) for the first 48 hours and twice daily for the rest of the study period (28 days). The OGTT was conducted as described (Watanabe et al., 2004).

Wounds were created on the back of each research subject under general anesthesia using intramuscular injection of $0.5 \mathrm{mg} / \mathrm{kg}$ of $2 \%$ Xylazine hydrochloride (Xyla-Ject, Adwia, Egypt) and $15 \mathrm{mg} / \mathrm{kg}$ of $10 \%$ Ketamine hydrochloride (Ketamina ${ }^{\circledR}$, Alfasan, Woerden, Holland). Dogs were premedicated with subcutaneous injection of $0.04 \mathrm{mg} / \mathrm{kg}$ of $1 \%$ atropine sulphate (Atropine Sulphate, Adwia, Egypt).
In each of the animal subjects, a total of 4 fullthickness wounds were created under aseptic conditions. Each of the wounds was $1.5 \mathrm{~cm} \times 1.5 \mathrm{~cm}$. Wounds were placed $5 \mathrm{~cm}$ apart from each other. Wounds were created on dogs back in the area corresponding to the thoracolumbar region. In each of the animal subjects of both alloxan-induced and control dogs, wounds were contaminated by topical application of the entire wound surface with 1-2 $\mathrm{g}$ of fresh dog feces under a bandage for 24 hours as described by Bischofberger et al. (2013). After 24 hours, bandages were removed and wounds were rinsed with sterile normal saline $(0.9 \% \mathrm{NaCl})$.

In each of the research subjects in the alloxaninduced group, wounds were randomly allocated to receive the following treatments: two wounds $(n=8)$ treated with $1-2 \mathrm{ml}$ of povidine iodine (HiGeen ${ }^{\circledR}$ Iodine 10\%, Households \& Toiletries Mfg. Co., Sukhtian, Jordan); two wounds $(\mathrm{n}=8)$ treated with $1-2 \mathrm{ml}$ raw Sidr honey (Al-Yahya Honey Factory, Abha, Kingdom of Saudi Arabia). Topical application of treatments started $24 \mathrm{~h}$ after wound created, twice daily for the first week, and then once daily for the rest of the study period (28 days). Wounds were left uncovered and allowed to heal by second intension. Control dogs were treated in similar protocol.

Wounds were grossly evaluated daily at the time of application for hyperemia, edema and exudate formation. In addition, the following observations were reported for each wound: the day initial granulation tissue appeared, the day granulation tissue was completed, the day initial epithelialization appeared and the day the wound was completely epithelialized (if achieved within the study period).

Wounds were digitally photographed using a digital camera (Canon, EOS 5SD, Canon USA Inc, USA) on days $0,7,14,21$ and 28 of the study. The unhealed wound area $\left(\mathrm{cm}^{2}\right)$ and the length of the advancing epithelium were measured using image analysis software (ImageJ, National Institutes of Health, USA). The epithelialization area $\left(\mathrm{cm}^{2}\right)$, wound area percentage and wound contraction percentage were calculated using previously published formulas (Kandemir et al., 2013)

The epithelialization area was calculated by subtracting the measured unhealed wound area at a given day from the initial unhealed area of the same wound (day 0 ). Wound area percentage was calculated using the formula [Wound area $(\%)=100 \times($ wound area on given day/initial wound area)]. The wound contraction rate was calculated using the formula $[(=$ $100 *$ (initial wound area -area of the given wound at the evaluation time)/initial wound area]. The described parameters were measured three times at each time point to obtain the mean measurement at a given day. 
Res. Opin. Anim. Vet. Sci., 2016, 6(8): 242-247.

At the end of the study, dogs were anesthetized and $5 \mathrm{~mm}$ diameter excisional skin biopsy samples were obtained from each of the described wounds. The biopsy samples were fixed in 10\% formalin solution and prepared for histopathological evaluation. Prepared slides were stained using Hematoxylin and Eosin (H\&E). For each slide, 8 randomly selected fields were evaluated using light microscopy. Histopathological scoring system was adopted to assess healing in terms of epithelialization, formation of granulation tissue, collagen deposition, inflammatory cells infiltration, angiogenesis and ulcer or abscess formation as previously reported (Kandemir et al., 2013).

\section{Statistical analysis}

All data were analyzed statistically using the GLM procedure of SAS System (2002) for Windows Release 8.1 (SAS Inst. Inc., Cary, NC). Data collected weekly (unhealed wound area $\left(\mathrm{cm}^{2}\right)$ and the length of the advancing epithelium, epithelialization area $\left(\mathrm{cm}^{2}\right)$, wound area in percentage and percentage of wound contraction) were analyzed as repeated measures. The model contained the effects of disease, treatments, time, and all interactions between disease, treatments and time. Histopathology scores (epithelialization, granulation tissue formation, collagen deposition, inflammatory cells infiltration, angiogenesis, and ulcer/abscess formation) were analyzed according to the completely randomized design. The model contained the effects of disease, treatments and disease. Means were computed using the LSMEANS option and separated using preplanned pair-wise comparisons of least squares means using t-tests.

\section{Results}

\section{Gross evaluation}

Wounds were evaluated for the presence of signs of inflammation (hyperemia, pain, edema and exudate formation). In both groups, signs of inflammation appeared to have subsided during the beginning of week 2 in honey-treated wounds while it persisted further into the end of week 2 and beginning of week 3 in iodine-treated wounds.

Overall, regardless of the treatment used, wounds in control dogs appeared to heal at a faster rate when compared with alloxan-induced dogs as indicated by earlier formation of granulation tissue and epithelialization. Honey-treated wounds appeared to have an accelerated granulation tissue and epithelialization rate compared to those treated using iodine. In alloxan-induced dogs, granulation tissue was initially observed during days 5-7, and 6-9 in honeytreated and iodine-treated wounds, respectively. Granulation tissue filled the wound at days 9-15 and 14-16 days in honey-treated and iodine-treated wounds respectively. Initial epithelialization was first observed during days 17-19, and 16-21in honey-treated and iodine-treated wounds, respectively. Epithelialization was completed only in one of the honey-treated and one of the iodine-treated wounds at days 27 and 28 respectively. While in the control group, initial granulation tissue appeared between days 5-6, and 6-7 in honey-treated and iodine-treated wounds respectively. Filling of wound bed with granulation tissue was observed between days 7-9, and 9-10 in

Table 1: Mean values of the evaluated digital imaging data of wounds of Alloxan-induced and control dogs treated by Sidr honey and iodine

\begin{tabular}{|c|c|c|c|c|c|}
\hline Parameter & Time (day) & $\begin{array}{c}\text { Alloxan } \\
\text { induced (honey) }\end{array}$ & $\begin{array}{c}\text { Alloxan } \\
\text { Induced (iodine) }\end{array}$ & Control (iodine) & Control (honey) \\
\hline \multirow[t]{5}{*}{ Unhealed wound area } & 0 & 2.21 & 2.25 & 2.27 & 2.22 \\
\hline & 7 & 1.57 & 1.78 & 1.97 & 2.06 \\
\hline & 14 & 1.01 & 1.05 & 0.44 & 0.57 \\
\hline & 21 & 0.50 & 0.66 & 0.13 & 0.24 \\
\hline & 28 & 0.29 & 0.22 & 0.05 & 0.11 \\
\hline \multirow[t]{5}{*}{ Wound area percentage } & 0 & 100.00 & 100.00 & 100.00 & 100.00 \\
\hline & 7 & 73.30 & 78.84 & 86.64 & 92.75 \\
\hline & 14 & 45.71 & 46.47 & 19.52 & 25.86 \\
\hline & 21 & 22.68 & 28.88 & 5.81 & 10.68 \\
\hline & 28 & 13.24 & 9.73 & 2.32 & 4.63 \\
\hline \multirow[t]{5}{*}{ Epithelialization area percentage } & 0 & 0.00 & 0.00 & 0.00 & 0.00 \\
\hline & 7 & 0.59 & 0.54 & 0.48 & 0.31 \\
\hline & 14 & 1.20 & 1.14 & 1.21 & 1.83 \\
\hline & 21 & 1.67 & 1.58 & 1.60 & 2.13 \\
\hline & 28 & 1.91 & 1.89 & 2.03 & 2.22 \\
\hline \multirow[t]{5}{*}{ Wound contraction percentage } & 0 & 0.00 & 0.00 & 0.00 & 0.00 \\
\hline & 7 & 26.70 & 32.16 & 13.36 & 7.25 \\
\hline & 14 & 54.29 & 47.84 & 80.48 & 74.14 \\
\hline & 21 & 75.55 & 69.47 & 93.85 & 89.48 \\
\hline & 28 & 86.48 & 86.61 & 97.68 & 95.18 \\
\hline
\end{tabular}


Res. Opin. Anim. Vet. Sci., 2016, 6(8): 242-247.

Table 2: Median scores of the evaluated histopathological parameters in wounds of Alloxan-induced and control dogs treated by Sidr honey and iodine

\begin{tabular}{lcccc}
\hline Parameters & $\begin{array}{c}\text { Alloxan } \\
\text { induced (honey) }\end{array}$ & $\begin{array}{c}\text { Alloxan } \\
\text { induced (iodine) }\end{array}$ & $\begin{array}{c}\text { Control } \\
\text { (honey) }\end{array}$ & $\begin{array}{c}\text { Control } \\
\text { (iodine) }\end{array}$ \\
\hline Epithelialization & 0.5 & 0.5 & 2 & 2 \\
Granulation tissue & 2.5 & 1.5 & 3 & 2.5 \\
Collagen deposition & 1 & 1 & 3 & 3 \\
Inflammatory cells infiltration & 3 & 3 & 1.5 & 1 \\
Angiogenesis & 1.5 & 1 & 3 & 2.5 \\
Ulcer or abscess & 3 & 3 & 0 & 0 \\
\hline
\end{tabular}

honey-treated and iodine-treated wounds respectively. Initial wound epithelialization started to appear at day 11-12 and 12-13 in honey-treated and iodine-treated wounds respectively. All wounds appeared to have completed epithelialization by the end of the study in non-diabetic dogs.

\section{Analysis of digital imaging}

Table 1 shows the data obtained from the digital imaging analysis for the evaluated parameters. Although there were no statistically significant differences in any of the evaluated parameters at each time point between honey and iodine-treated wounds in both groups, the analysis of the data clearly shows that the unhealed wound area and wound area percentage was higher in iodine-treated wounds while epithelialization area percentage and wound contraction percentage was higher in honey-treated wounds. There is a significant difference in the evaluated parameters at progressive time points (day 0, day 7, day 14, day 21, day 28).

\section{Histopathological evaluation}

In general, wounds in both groups exhibited similar trends of healing. At the end of the experiment, the surgical wounds were partially or completely closed. The surgical wounds were partially or completely covered by normal to hyperplastic stratified squamous epithelia overlying relatively normal dermis. The dermis was 2 times thicker than normal because of fibroplasia and was devoid of any adnexal structures.

The histopathological scores of epithelialization, granulation tissue formation, collagen deposition, inflammatory cells infiltration, angiogenesis, and ulcer/abscess formation in wounds of both groups treated by Sidr honey and iodine are shown in Table 2 . Honey and iodine significantly improved epithelialization in control dogs while a significant difference in epithelialization was not observed in alloxan-induced dogs between any of the treatments used in the study. Honey significantly improved granulation tissue formation in alloxan-induced dogs compared to iodine. There was significantly more collagen in honey and iodine treated wounds. There was variable degrees of inflammatory cell infiltration in all wounds regardless of treatment used and dogs' group. Honey and iodine significantly affected ulcer/abscess formation in control dogs but not in alloxan-induced dogs. Wounds in alloxan-induced dogs had significantly more ulcer/abscess formation.

\section{Discussion}

The present study was undertaken to evaluate whether Sidr honey promote wound healing following alloxan-induced diabetes mellitus in dogs. The findings of the research reported here substantiate the use of Sidr honey for management of contaminated wounds in both groups. Although there was no statistical significant differences, application of Sidr honey appeared to promote different stages of healing of contaminated wounds. In here, honey seemed to have enhanced healing by subsiding inflammation faster, promoting earlier growth of granulation tissues and stimulating faster epithelialization when compared with iodine.

Honey is a sweat viscous natural product produced by the honey bees. Different types of honey have been reported to vary in their colour, potency, chemical and physical properties according to its plant source and geographical region (Molan, 1992). Sidr honey is considered a mono-floral type honey derived from Sidr trees. Sidr tree is known as "Christ's thorn" and belong to the Ziziphus family of plants which has been reported to grow in coastal desert and semi-desert areas including Arabian Peninsula (Roshan et al., 2013). Recently, Sidr honey was found to have the highest $\mathrm{pH}$, lowest total phenolic and flavonoid content, and comparable mineral and vitamins when compared to four types of honey (AL-Waili et al., 2013).

Honey is widely available natural product that has been shown a variety of medicinal properties helpful to promote wound healing and other aspects of health. Although different types of honey vary in their contents, pure natural honey is mainly composed of approximately $80 \%$ sugar, $20 \%$ water and traces of minerals and vitamins (Hananeh et al., 2015). Combined effect of high sugar content and lower water content has been suggested to create high osmolarity conditions in the wounds and thus absorbs fluids and exudates from wounds (Shukrimi et al., 2008). Earlier 
reduction of edema, higher scores of formation of granulation tissues and angiogenesis was observed in our study in the honey- treated wounds when compared with iodine-treated wounds in both alloxan-induced and control groups. The findings presented here are similar to the finding reported in human literature where wounds in patients with diabetes mellitus heals at slower rates and application of topical honey on wounds enhanced wound healing (Shukrimi et al., 2008). Slower wound healing in diabetic patients could be attributed to many factors including infection, ischemia or immuno-suppression (Shukrimii et al., 2008). A systematic review of 27 randomized clinical trials evaluating the effect of iodine on wound healing concluded that iodine did not lead to a reduction or prolongation of wound-healing time when compared with other antiseptic agents however iodine was inferior to crude honey in reducing bacterial count and wound size (Vermeulen et al., 2010).

Here, application of honey on the wounds was tolerable by all dogs. No signs of local allergies or systematic signs were observed after topical application of honey on dogs. In human medicine, although uncommon, honey has been implicated to occasionally produce signs of systemic intoxication due to dormant endospores of Clostridium botulinum or to contamination by herbal drugs such as grayanotoxins from Ericaceae plants (Shapiro et al., 1998). Also, allergy such as contact dermatitis or urticarial has been reported and may occur due to the presence of pollen and bee protein (Pasolini et al., 2004; Matos et al., 2015). In our study, we have not experienced any of those concerns. In addition, honey did not appear to induce pain or discomfort upon its application on the wound.

Limitations of the study reported here are only few and inconsequential. Although the number of the research subjects included is small, the findings highlighted the effect of topical application of Sidr honey in alloxan-induced diabetes mellitus dogs. In our study design presented here, in each of the research subjects, two wounds were created to receive the same type of the treatment to maximize the sample size. Also, the findings of this study raise a valid debatable issue whether the observed effect are due to Sidr honey originating from the Arabian Peninsula or could these results be generalized to other types of honey originating in other parts of the globe. Adequately answering this issue would require comparative controlled studies to evaluate different types of honey on wound healing from different regions of the globe.

The Significance of the study reported here is that it is the first study to evaluate the healing of contaminated wound in alloxan-induced diabetes in dogs using Sidr honey. In conclusion, this study has shown a promising beneficial effect of Sidr honey.

\section{Acknowledgment}

The authors gratefully acknowledge the financial support provided by the Deanship of Research of Jordan University of Science and Technology.

\section{References}

AL-Waili N, Al Ghamdi A, Ansari MJ, Al-Attal Y, AlMubarak A, Salom K (2013) Differences in composition of honey samples and their impact on the antimicrobial activities against drug multiresistant bacteria and pathogenic fungi. Arch Med Res 44: 307-16.

Alzubier A, Okechukwu P (2011) Investigation of antiinflammatory, antipyretic and analgesic effect of Yemeni Sidr Honey. World Acad Sci Eng Technol 5: 41-46.

Bani Ismail Z, Hananeh W, Alshehabat M, Daradka M, Ali J (2015) Short -term clinical and pathological alterations associated with a single intravenous injection of alloxan monohydrate in dogs. HVM Bioflux 2: 70-78.

Bischofberger AS, Dart CM, Perkins NR, Kelly A, Jeffcott L, Dart AJ (2013) The effect of short- and long-term treatment with manuka honey on second intention healing of contaminated and noncontaminated wounds on the distal aspect of the forelimbs in horses. Vet Surg 2: 154-60.

Hananeh W, Bani Ismail Z \& Alshehabat M (2015) Effects of Sidr Honey on Second-Intention Healing of Contaminated Full-Thickness Skin Wounds in Healthy Dogs. Bulletin Veterinary Institute Pulawy 3: 433-39.

Kamaratos A, Konstantinos N, Tzirogiannis S (2014) Manuka Honey-Impregnated Dressings in the Treatment of Neuropathic Diabetic Foot Ulcers. Int Wound J 11: 259-63.

Kandemir FM, Sagliyan A, Ozkaraca M, Gunay C, Han MC, Benzer F (2013) Effects of oral administrations of pomegranate seed extract on surgical wound healing in rabbits. Revue Méd Vét 164: 400-408.

Margolis DJ, Allen-Taylor L, Hoffstad O, Berlin JA (2015) Diabetic neuropathic foot ulcers and amputation. Wound Repair Regen 13: 230-6.

Margolis DJ, Bartus C, Hoffstad O, Malay S, Berlin JA (2005) Effectiveness of recombinant human platelet-derived growth factor for the treatment of diabetic neuropathic foot ulcers. Wound Repair Regen 6: 531-6.

Matos D, Serrano P, Menezes Brandão F (2015) A case of allergic contact dermatitis caused by propolisenriched honey. Contact Dermatitis 1: 59-60.

Molan P (1992) The antibacterial activity of honey: 2. Variation in the potency of the antibacterial activity. Bee World 2: 59-76. 
Nelson RW, Reusch CE (2014) Animal models of disease: Classification and etiology of diabetes in dogs and cats. J Endocrinol 3: T1-9.

Pasolini G, Semenza D, Capezzera R, Sala R, Zane C, Rodella R, Calzavara-Pinton P (2004) Allergic contact cheilitis induced by repeated contact with propolis-enriched honey. Contact Dermatitis 5: 322-3.

Roshan AR, Gad HA, El-Ahmady SH, Khanbash MS, Abou-Shoer MI, Al-Azizi M (2013) Authentication of monofloral Yemeni Sidr honey using ultraviolet spectroscopy and chemometric analysis. J Agric Food Chem 32: 7722-9.

Shapiro RL, Hatheway C, Swerdlow DL (1998) Botulism in the United States: a clinical and epidemiologic review. Ann Intern Med 3: 221-8.
Shukrimi A, Sulaiman AR, Halim AY, Azril A (2008) A comparative study between honey and povidone iodine as dressing solution for Wagner type II diabetic foot ulcers. Med J Malaysia 1: 44-6.

Ullah F, Ayesha K \& Fawad R (2015) Knowledge of diabetic complications in patients with diabetes mellitus. J Ayub Med College Abbottabad 27: 360-63.

Vermeulen H, Westerbos S \& Ubbink D (2010) Benefit and Harm of Iodine in Wound Care: A Systematic Review. J Hosp Infect 76: 191-99.

Watanabe D, Nakara H, Yamaguchi Y, Akagi K, Hoshiya T, Nagashima Y, Okaniwa A, Yoshikawa $\mathrm{H}$ (2004) The Pathological features of alloxan Diabetes in Beagle Dogs. J Toxicol Pathol 17: 187195. 